\title{
Effects of Environmental Regulation on Green Total Factor Productivity: An Evidence from the Yellow River Basin, China
}

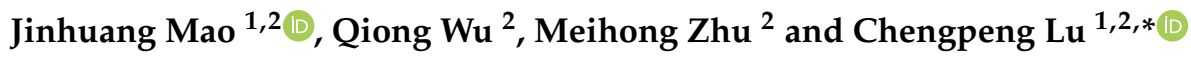 \\ 1 Institute of County Economic Development \& Rural Revitalization Strategy, Lanzhou University, \\ Lanzhou 730000, China; maojh@lzu.edu.cn \\ 2 School of Economics, Lanzhou University, Lanzhou 730000, China; qwu20@lzu.edu.cn (Q.W.); \\ zmh991121@163.com (M.Z.) \\ * Correspondence: lcp@lzu.edu.cn
}

check for updates

Citation: Mao, J.; Wu, Q.; Zhu, M.; Lu, C. Effects of Environmental Regulation on Green Total Factor Productivity: An Evidence from the Yellow River Basin, China. Sustainability 2022, 14, 2015. https: / /doi.org/10.3390/ su14042015

Academic Editor: Miguel

Amado

Received: 9 January 2022

Accepted: 7 February 2022

Published: 10 February 2022

Publisher's Note: MDPI stays neutral with regard to jurisdictional claims in published maps and institutional affiliations.

Copyright: (c) 2022 by the authors. Licensee MDPI, Basel, Switzerland. This article is an open access article distributed under the terms and conditions of the Creative Commons Attribution (CC BY) license (https:// creativecommons.org/licenses/by/ $4.0 /)$.

\begin{abstract}
Based on the data of 59 prefecture-level cities in the Yellow River Basin from 2011 to 2019, this paper uses the Slack Based Measure-Global Malmquist Luenberger (SBM-GML) model to measure green total factor productivity (GTFP) of the cities. Under the space-time concept of the Basin, heterogeneity analysis of the upper, middle and lower reaches of the Yellow River Basin is conducted. On this basis, a panel Tobit model is constructed to analyze the impact of environmental regulation on GTFP in the whole basin, upstream region, middle region and downstream region. The results show that the intensity of environmental regulation in the Yellow River Basin increases gradually, which is the highest in the lower reaches, followed by the middle reaches; spatially, the intensity of environmental regulation shows a certain aggregation trend. The green economic growth is realized in the whole basin, and the green technology progress effect is the driving factor of GTFP. The GTFP distribution in the upstream region is relatively concentrated, showing a slow upward trend. The distribution of GTFP in the middle reaches is discrete, and the annual difference is large. In the downstream region, it shows a trend of decline first and then increase. Environmental regulation promotes GTFP in the whole basin, upper, middle and lower reaches, accompanied by certain spatial differences. The Yellow River Basin breaks through the cost effect brought by environmental regulation and triggers technological innovation, thereby enhancing GTFP; the "Porter hypothesis" has been verified in the Yellow River Basin.
\end{abstract}

Keywords: environmental regulation; GTFP; regional heterogeneity; Yellow River Basin; China

\section{Introduction}

Environmental regulation is a kind of constraint which aims at environmental protection, targets individuals or organizations, and exists in the form of tangible system or intangible consciousness [1]. Different scholars have classified environmental regulation from different perspectives, among which the most representative is Francisco's classification standard. He divides environmental regulation into command and control environmental regulation, market-driven environmental regulation, and voluntary environmental regulation policy [2]. With the worsening and prominent environmental problems, since the 1970s, countries around the world have gradually paid attention to the protection and regulation of the environment. China is one of the first developing countries to take the protection of the environment as a basic national policy, and is a party and promoter of the United Nations Framework Convention on Climate Change and the Kyoto Protocol [3]; accordingly, its environmental regulations are increasingly stringent [4]. In 2013, China's economy entered a new normal. The traditional total factor productivity (TFP) cannot accurately measure the actual quality of economic growth because it does not consider the impact of energy consumption and pollution emissions on economic growth. In this context, energy consumption and pollution emissions are included in the traditional TFP 
accounting framework; considering the increase of expected output and the decrease of unexpected output, green total factor productivity (GTFP) is obtained to measure the quality of economic development. As the largest developing country in the world, China has yet to complete its urbanization and industrialization process due to large regional differences. Some environmental measures are taken at the cost of development or transfer, which deviates from the original intention of improving the quality of economic growth. Therefore, environmental regulation and development must be weighed, and exploring the relationship between environmental regulation and GTFP is of great significance to achieve high-quality development of the Yellow River Basin.

Scholars supporting the "Porter hypothesis" believe that environmental regulation can stimulate the technological innovation effect of enterprises, and then improve green TFP [5-7]. Environmental regulation stimulates firms to increase TFP [8,9]. Relevant calculations confirm that China's manufacturing industry has reached the Porter turning point, and strong environmental regulation promotes GTFP growth in the manufacturing industry $[10,11]$. GTFP data from 30 Chinese provinces also support the "facilitation theory" [12]. However, as an external pressure, environmental regulation will change the production decisions of enterprises, resulting in a sudden increase in production costs. In the short term, it will force enterprises to reduce the input of production factors, change their production behaviors, and increase product prices due to unreasonable resource allocation, which reduce the market competitiveness of enterprises, and the TFP of enterprises will decrease accordingly [13]. Foreign studies have found that environmental regulation reduces productivity growth in US manufacturing [14,15]. From the perspective of behavioral economics, pollution investment will affect the production of enterprises in the short term; therefore, managers tend to choose short-term investment decisions, which have a negative impact on the total factors of enterprises [16]. Domestic research shows that due to the excessive intensity of environmental regulation and unreasonable use of environmental regulation tools, the stimulation of industrial total factor productivity in the western region is insufficient [17]. Using the long-term equilibrium relationship model, the results show that although environmental regulation can lead to innovation compensation, it cannot offset the cost effect, resulting in a slight decline in GTFP [18].

Still, related research still found that the impact of environmental regulation on GTFP is uncertain due to time, geographical differences and other factors. The impact of different intensity and type of environmental regulation on GTFP may be opposite $[19,20]$. In different industry conditions and time points, there are spatial and temporal differences in the impact of environmental regulation on enterprise productivity [21]. Additionally, the implementation of environmental regulation often has a time effect, the role of environmental regulation to play in a long time-range [5]. Huang et al., using the Slack Based Measure-Luenberger (SBM-L) model to measure the green TFP of the industrial sector, carried out an empirical analysis through the PVAR model, and found that the impact of environmental regulation on green TFP has time difference, which plays a promoting role in the short-term and cannot promote its sustained growth in the long-term [22].

The Fifth Plenary Session of the 18th CPC Central Committee pointed out that we must adhere to the basic national policy of saving resources and protecting the environment, and put forward five development concepts of "innovation, coordination, green, open and sharing". The Yellow River Basin is an important energy base in China. Considering the overall situation of national development, the Yellow River Basin plays a very important role in China's economic and social development and ecological security. It undertakes the task of providing good ecological services and ecological products for the whole country. However, due to its special natural conditions and acquired social functions, the basin development foundation is poor, the level of industrial development is low, the incidence of relative poverty is high, the production and life are faced with water resources constraints, and there is a dislocation between ecological protection and economic development, which is constrained by strong environmental regulations. Especially in the face of serious ecological and environmental problems, air quality and water quality are seriously reduced, 
and high input in the production process does not necessarily bring high output, i.e., the low efficiency phenomenon. The government has issued environmental protection policies and guidelines, corporate social responsibility is highlighted, and the enhancement of public awareness of environmental protection will become tangible or intangible environmental regulation, which has a profound impact on economic activities in the Yellow River Basin, especially productivity. Under this background, studying the impact of environmental regulation on GTFP in the Yellow River Basin is conducive to achieving a win-win situation of ecological optimization and economic growth in the Yellow River Basin.

At present, scholars at home and abroad have done a lot of research on the relationship between environmental regulation and GTFP, and the research results are abundant, which provides rich demonstration resources for this study. Research on environmental regulation at home and abroad is mostly based on the national and provincial levels, and there are few studies on the city level. In the measurement of environmental regulation intensity, it is limited to use only a single indicator to replace it. Therefore, this paper adopts the entropy method, synthesizes existing studies, and takes the calculated environmental regulation comprehensive intensity index as the indicator to measure the environmental regulation intensity of prefecture-level cities. For the study of GTFP, it is more appropriate to use Data Envelopment Analysis (DEA) to measure total factor productivity for macro data [23]. The SBM model not only considers the unexpected output, but also can effectively identify the difference of enterprise environmental efficiency [24]. Combining the advantages of comparability of Global Malmquist Luenberger (GML) index and avoiding technological regression, the DEA-SBM model and GML index were used to calculate and decompose GTFP of prefecture-level cities, and decompose it to analyze the temporal and spatial evolution trend of GTFP in the Yellow River Basin. In environmental regulation and the GTFP study, domestic and foreign literature is rich, but there are few studies on the Yellow River Basin, and some studies on the Yellow River Basin do not accurately locate the Yellow River Basin, using the data on the level of province or including all cities flowing through eight provinces. Considering the regional heterogeneity of the Yellow River Basin, this paper divides the research objects into three types of cities: upstream, midstream and downstream, to obtain the heterogeneity of the impact of environmental regulation on GTFP and its causes, and puts forward countermeasures and suggestions to promote ecological protection and high-quality development of the Yellow River Basin from the aspects of environmental regulation and GTFP improvement.

\section{Study Area and Methods}

\subsection{Study Area}

The planning scope of the Outline of Ecological Protection and High-quality Development Plan of the Yellow River Basin issued by The CPC Central Committee and The State Council of China is the relevant county-level administrative regions in nine provinces and regions of Qinghai, Sichuan, Gansu, Ningxia, Inner Mongolia, Shanxi, Shaanxi, Henan and Shandong that the main and tributaries of the Yellow River flow through. Scholars have selected and adjusted the scope of counties and cities specifically involved in the Yellow River Basin according to the needs of the research. Scholars have different determinations of the scope in the study of the Yellow River Basin. In this paper, the Yellow River Basin administrative division list in Yellow River Yearbook 1995 is taken as an important basis, and the scope of the Yellow River Basin is finally determined as 59 prefecture-level cities, prefectures and leagues by referring to the practices of some scholars. The data of Gannan Tibetan Autonomous Prefecture, Linxia Hui Autonomous Prefecture in Gansu Province, Aba Tibetan Qiang Autonomous Prefecture in Sichuan Province, Haibei Tibetan Autonomous Prefecture in Qinghai Province, Huangnan Tibetan Autonomous Prefecture, Hainan Tibetan Autonomous Prefecture, Guoluo Tibetan Autonomous Prefecture, Yushu Tibetan Autonomous Prefecture, Haixi Mongolian and Tibetan Autonomous Prefecture, and Alxa League in Inner Mongolia are seriously missing. If other methods are adopted to complete the data, large errors will be caused to the research results. Secondly, industrial 
pollution is the main source of environmental pollution. Ethnic minority areas often have low levels of industrial development and light industrial pollution. The ten samples removed will not have a great impact on the research and core issues in this paper. Therefore, the 10 prefecture-level administrative regions were removed from the research scope, and 59 prefecture-level cities were selected as the research objects, in Table 1, these cities are divided into the upper, middle and lower reaches of the Yellow River.

Table 1. Division of 59 prefecture-level cities in the Yellow River Basin.

\begin{tabular}{cl}
\hline \multicolumn{1}{c}{ Regions } & \multicolumn{1}{c}{ Cities } \\
\hline \multirow{2}{*}{ Upper Reaches } & $\begin{array}{l}\text { Lanzhou, Baiyin, Tianshui, Wuwei, Pingliang, Qingyang, Dingxi, Longnan, } \\
\text { Hohhot, Baotou, Ulanqab, Ordos, Bayannaoer, Wuhai, Yinchuan, Shizuishan, } \\
\text { Wuzhong, Guyuan, Zhongwei, Xining, Haidong. }\end{array}$ \\
& $\begin{array}{l}\text { Zhengzhou, Luoyang, Jiaozuo, Sanmenxia, Taiyuan, Yangquan, Changzhi, } \\
\text { Middle Reaches } \\
\text { Jincheng, Shuozhou, Jinzhong, Yuncheng, Xinzhou, Linfen, LvLiang, Xi'an, } \\
\text { Tongchuan, Baoji, Xianyang, Weinan, Yan'an, Yulin, Shangluo. } \\
\text { Lower Reaches } \\
\text { Kaifeng, Anyang, Hebi, Xinxiang, Puyang, Jinan, Zibo, Dongying, Jining, } \\
\text { Taian, Laiwu, Linyi, Dezhou, Liaocheng, Binzhou, Heze. }\end{array}$ \\
\hline
\end{tabular}

\subsection{Entropy Method}

The methods for measuring the intensity of environmental regulation mainly include the single indicator method, the alternative indicator method, and the comprehensive measurement method. Since the comprehensive measurement method has the advantages of comprehensiveness and objectivity, this paper adopts the comprehensive measurement method, which is used for reference and improvement of Zhao [25] to calculate the comprehensive intensity index of environmental regulation in prefecture-level cities by the entropy method.

The specific steps of the entropy method are as follows:

The first step is to construct the initial index data matrix. Suppose there are $\mathrm{m}$ cities and $\mathrm{n}$ indexes. Then $X=\left(x_{i j}\right)_{m \times n}(1 \leq i \leq m, 1 \leq j \leq n)$, and $x_{i j}$ is the $j t h$ indicator for the $i$ city.

The second step is to standardize the data before the operation due to the differences in dimension, magnitude and positive and negative numbers between the indicators. The range transformation method is used to standardize the initial data. The method is as follows:

If the indicator is a positive indicator, then:

$$
b_{i j}=\frac{x_{i j}-\min x_{i j}}{\max x_{i j}-\min x_{i j}}(j=1,2, \ldots n)
$$

If the index is negative, then:

$$
b_{i j}=\frac{\max x_{i j}-x_{i j}}{\max x_{i j}-\min x_{i j}}(j=1,2, \ldots n)
$$

The maximum and minimum values in the formula refer to the value of $j$. At the same time, for the convenience of operation, the inverse of the negative index is uniformly put into the initial matrix, and then the positive index calculation method is uniformly used to calculate the proportion of the $i$ regional index value under the $j$ index in the initial matrix $p_{i j}$ :

$$
p_{i j}=\frac{b_{i j}}{\sum_{i=1}^{m} b_{i j}}
$$

Defining standardized matrices $p=\left(p_{i j}\right)_{m \times n^{\prime}} 0 \leq p_{i j} \leq 1$. 
The third step is to calculate the entropy value of evaluation index $j$ :

$$
e_{j}=(1 / \ln m) \sum_{i=1}^{m} p_{i j} \ln p_{i j}\left(0 \leq e_{i j} \leq 1\right)
$$

If $p_{i j}=0$, then $p_{i j} \ln p_{i j}=0$.

The fourth step is to calculate the difference coefficient of evaluation index $j$ :

$$
k_{j}=1-e_{j}
$$

The fifth step is to define the weight of the evaluation index:

$$
w_{j}=k_{j} / \sum_{j=1}^{m} k_{j}
$$

\subsection{Environmental Technology Equation}

We use each city as a DMU to construct production frontiers. The input-output combination is composed of input factor $X$, undesirable output $\gamma$ and pollution emission $O$. At this time, each decision making unit uses $\mathrm{N}$ input factors $X, x_{n i}=(n=1,2, \ldots, N) \in R^{+}$, $i$ represents $i$ city, obtaining $M$ expected outputs $y_{m i}=(m=1,2, \ldots, M) \in R^{+}$, and $Z$ undesired outputs, namely pollutant emissions $o_{z i}(z=1,2, \ldots Z) \in R^{+}$. In this paper, the expected output is the GDP of prefecture-level cities, the unexpected output is the industrial wastewater discharge of prefecture-level cities, and the input factors are capital input, labor input, energy input and water resource input. This paper is based on the Constant Returns to Scale (CRS) production technology function proposed by Charnes [26] in 1978, and drawing on the practice of Zhou [27], the production possibility set $P(x)$ is constructed:

$$
P(X)=\left\{\left(y_{m i}, o_{z i}\right): x_{n i} \rightarrow\left(y_{m i}, o_{z i}\right)\right\}, x_{n i} \in R^{+}, y_{m i} \in R^{+}, o_{z i} \in R^{+}
$$

Assuming that the undesirable output of each city in production is weak disposability:

$$
\left(y_{m i}, o_{z i}\right) \in P(X),\left(\theta y_{m i}, \theta o_{z i}\right) \in P(X), 0 \leq \theta \leq 1
$$

Assuming that the undesirable output of each city in production is strong disposability, pollutant emissions can be ignored at this time:

$$
\left(y_{m i}, o_{z i}\right) \in P(X),\left(y_{m i}^{*}, o_{z i}\right) \in P(X), y_{m i}^{*} \leq y_{m i}
$$

Assuming that expected output and pollutant emissions are associated with each other, that is, they are "zero combined":

$$
\left(y_{m i}, o_{z i}\right) \in P(X) \text {, if } o_{z i}=0 \text {, then } y_{m i}=0
$$

Under the above conditions, in period $t, t=(1,2, \ldots T)$, the input -output combination of the $i$ th decision-making unit $P(X)$ is expressed as $\left(x_{i}^{t}, y_{i}^{t}, o_{i}^{t}\right)$, and DEA is used to model the production possibility set that meets the constraints to obtain:

$$
P^{t} X^{t}=\left\{\begin{array}{c}
\left(Y^{t}, O^{t}\right): \sum_{i=1}^{i} \lambda_{i m}^{t} y_{i m}^{t} \geq y_{i m}^{t}, \forall m ; \sum_{i=1}^{i} \lambda_{i}^{t} o_{i z}^{t} \geq o_{i z}^{t}, \forall z ; \\
\sum_{i=1}^{i} \lambda_{i}^{t} x_{i n}^{t} \geq x_{i n^{t}}^{t}, \forall n
\end{array}\right\}
$$

where $x=\left(x_{1}, \ldots, x_{N}\right), y=\left(y_{1}, \ldots, y_{M}\right), o=\left(o_{1}, \ldots, o_{Z}\right) . \lambda_{i}^{t}$ represents cross-section observations. 


\subsection{Slack Based Model (SBM)}

To overcome the radial and angular defects of the distance function, Tone $[28,29]$ proposed the SBM model, and incorporated the slack variables into the analysis framework for the first time. The SBM model considering energy input and environmental undesirable output is defined as:

$$
\begin{gathered}
\vec{S}_{C}^{t}\left(x^{t, i^{\prime}}, y^{t, i^{\prime}}, o^{t, i^{\prime}}, g^{x}, g^{y}, g^{o}\right)=\max _{s_{n}^{x} s_{m}^{y} s_{z}^{o}} \frac{\frac{1}{N} \sum_{n=1}^{N} \frac{s_{n}^{x}}{g_{n}^{x}}+\frac{1}{M+Z}\left(\sum_{m=1}^{M} \frac{s_{m}^{y}}{g_{m}^{y}}+\sum_{z=1}^{Z} \frac{s_{z}^{o}}{g_{z}^{o}}\right)}{2} \\
\text { s.t. } \sum_{i=1}^{I} \lambda_{i}^{t} x_{i n}^{t}+s_{n}^{x}=x_{i n}^{t}, \forall n ; \sum_{i=1}^{I} \lambda_{i}^{t} y_{i m}^{t}-s_{m}^{y}=y_{i m}^{t}, \forall m ; \sum_{i=1}^{I} \lambda_{i}^{t} o_{i z}^{t}-s_{z}^{0}=o_{i z}^{t}, \forall z ; \\
\sum_{i=1}^{I} \lambda_{i}^{t}=1, \lambda_{i}^{t} \geq 0, \forall i ; s_{n}^{x} \geq 0, \forall n ; s_{m}^{y} \geq 0, \forall m ; s_{o}^{z} \geq 0, \forall z
\end{gathered}
$$

where $\vec{S}_{C}^{t}$ is the directional distance function based on constant returns to scale, $\left(x^{t, i \prime}, y^{t, i \prime}, o^{t, i \prime}\right)$ represents input vector, expected output vector, and undesirable output vector for each province, $\left(g^{x}, g^{y}, g^{z}\right)$ denotes the direction vector of input and non-expected output reduction and expected output increase, respectively, $\left(s_{n}^{x}, s_{m}^{y}, s_{z}^{o}\right)$ represent the slack vector of input, expected output and non-expected output, $\left(s_{n}^{x}, s_{m}^{y}, s_{z}^{o}\right)$ is greater than zero, indicating that the input and pollution of the boundary are less than the actual input and pollution, and the output of the boundary is greater than the actual output. Therefore, it represents the amount of excessive input, excessive pollution and insufficient output.

\subsection{Global Malmquist-Luenberger Index}

Based on the production possibility set constructed above, the global production technology set is constructed, and the global environmental production technology is constructed as $P^{G}(x)=p^{1}\left(x^{1}\right) \cup p^{2}\left(x^{2}\right) \cup \cdots \cup p^{T}\left(x^{T}\right)$, where $t=1,2, \ldots, T, G M L$ index is expressed as:

$$
G M L^{t, t+1}=\frac{1+D^{G}\left(x^{t}, y^{t}, o^{t}\right)}{1+D^{G}\left(x^{t+1}, y^{t+1}, o^{t+1}\right)}
$$

$D^{G}\left(x^{t}, y^{t}, o^{t}\right)$ and $D^{G}\left(x^{t+1}, y^{t+1}, o^{t+1}\right)$ represent global directional distance function for periods $t$ and $t+1$. GML $>1$ indicates GTFP growth in the city from period $t$ to $t+1$. $G M L=1$ represents GTFP growth in the city remains unchanged from period $t$ to $t+1$, $G M L<1$ indicates GTFP declined from period $t$ to $t+1$.

The $G M L^{t, t+1}$ index can be further decomposed into the product of $G E C^{t, t+1}$ global efficiency change index and $G T C^{t, t+1}$ global technology progress index.

$$
\begin{gathered}
G E C^{t, t+1}=\frac{1+s_{c}^{t}\left(x^{t}, y^{t}, o^{t}, g^{x}, g^{y}, g^{o}\right)}{1+s_{c}^{t}\left(x^{t+1}, y^{t+1}, o^{t+1}, g^{x}, g^{y}, g^{o}\right)} \\
G T C^{t, t+1}=\frac{\left[1+S_{c}^{G}\left(x^{t}, y^{t}, o^{t}, g^{x}, g^{y}, g^{o}\right) / 1+S_{c}^{t}\left(x^{t}, y^{t}, o^{t}, g^{x}, g^{y}, g^{o}\right)\right]}{\left[1+S_{c}^{G}\left(x^{t+1}, y^{t+1}, o^{t+1}, g^{x}, g^{y}, g^{o}\right) / 1+S_{c}^{t+1}\left(x^{t+1}, y^{t+1}, o^{t+1}, g^{x}, g^{y}, g^{o}\right)\right]}
\end{gathered}
$$

where $G E C^{t, t+1}$ or $G T C^{t, t+1}$ greater than 1 means efficiency improvement (technical progress) from $t$ stage to $t+1$ stage, equal to 1 means efficiency unchanged (technology unchanged), and less than 1 means efficiency decreased (technology recession).

\subsection{Tobit Model}

Because the explanatory variable used in this paper is the GTFP of each city, which has the characteristics of non-negative truncation, the biased estimation results will be obtained by using the least square method. Therefore, this paper chooses to build the Tobit model. 
We have added the Hausman test. After the Hausman test, the P value of the whole basin is 0.3939 , which is much larger than 0.1 . The result rejects the null hypothesis of fixed effects, and the random effect Tobit model should be selected in this paper.

Therefore, this paper establishes the general random effect Tobit model as follows:

$$
\begin{gathered}
y_{i t}^{*}=\beta_{0}+\beta_{k} x_{i t}+\varepsilon_{i t} \\
y_{i t}=\left\{\begin{array}{c}
y_{i t}^{*}, \text { if } y_{i t}^{*}>0 \\
0, \text { if } y_{i t}^{*} \leq 0
\end{array}\right\}
\end{gathered}
$$

In order to explore the effect of environmental regulation and other influencing factors on green total factor productivity in the Yellow River Basin, the model is set as the following form:

$$
y_{i t}^{*}=\beta_{0}+\beta_{1} e r_{i t}+\beta_{2} \text { tec }_{i t}+\beta_{3} \ln \text { capital }_{i t}+\beta_{4} \ln e d u_{i t}+\beta_{5} b e_{i t}+\beta_{6} f d_{i t}+\beta_{7} k e f z_{i t}+\varepsilon_{i t}
$$

\subsection{Data Source and Processing}

The research object of this paper is 59 prefecture-level cities in the Yellow River Basin from 2011 to 2019, excluding some minority areas. The data of this paper comes from the 2011-2019 China Urban Statistical Yearbook, the provincial statistical yearbook and the provincial Main Ecological Function Area Planning, and the water resources bulletin.

For the measurement index of environmental regulation intensity, we select industrial wastewater emissions, industrial sulfur dioxide emissions, industrial soot emissions, industrial solid waste utilization rate, centralized sewage treatment rate and harmless treatment rate of domestic garbage of 59 prefecture-level cities in the Yellow River Basin from 2011 to 2019 , as evaluation indexes. Among them, industrial wastewater emissions, industrial sulfur dioxide emissions, and industrial soot emissions are positive indicators, while the utilization rate, the centralized sewage treatment rate and the harmless treatment rate of domestic garbage are negative indicators. The missing data are supplemented by the linear interpolation method. Since the carbon emission trading system is not fully implemented, carbon dioxide is not the object of environmental regulation policy, at least in the research cycle, and cannot be used as a variable to measure the intensity of environmental regulation.

The measurement indicators of GTFP are divided into input indicators and output indicators. The input indicators are capital input, labor input and resource and energy input, and the output indicators are expected output and undesirable output. The expected output in this paper is measured by the GDP of prefecture-level cities, and the price is fixed to 2010 by the GDP index. The undesired output is measured by the discharge of industrial wastewater from 59 prefecture-level cities. Water resources in the Yellow River Basin are the main shortcomings that restrict the economic development and ecological environment protection process of each city. In order to avoid the dilution of other pollutant emissions on the calculation results, the discharge of industrial wastewater is taken as the index to measure the undesired output. Input factors are as follows: (1) Capital input. When calculating the capital input, the perpetual inventory method (PIM) is adopted to estimate the fixed capital stock of each city, and the formula is $K_{t}=K_{t-1}(1-\delta)+I_{t}{ }^{\prime}$, where $K_{t-1}$ is the initial capital stock of $t-1$ year, $\delta$ is the depreciation rate of fixed assets, and $I_{t}{ }^{\prime}$ is the price adjusted constant investment flow. (2) Labor input is measured by the number of employees in urban units in 59 prefecture-level cities in the Yellow River Basin from 2011 to 2019. (3) Energy input is measured by the total social electricity consumption of 59 prefecture-level cities in the Yellow River Basin from 2011 to 2019. (4) The input of water resources is measured by the production water consumption of 59 prefecture-level cities in the Yellow River Basin from 2011 to 2019. The total water consumption of prefecture-level cities is deducted from the urban public water consumption, residential water consumption and ecological environment water consumption to obtain the total water consumption for production. 
The change of GTFP in the Yellow River Basin is affected by many factors. To explore the effect of environmental regulation and other influencing factors on GTFP in the Yellow River Basin, the Tobit model variables are selected as follows:

Explained variable: Green total factor productivity (GTFP)—expressed by the GML index calculated based on SBM directional distance function and represents regional economic development quality.

Explanatory variable: Environmental regulation intensity index (er) - the comprehensive intensity index of environmental regulation calculated by the entropy method. The larger the comprehensive intensity index is, the higher the intensity of regional environmental regulation is.

Control variable: Science and technology input (tec) - measured by the proportion of science and technology expenditure in the local financial expenditure of each city. Generally speaking, science and technology input has a positive effect on the improvement of green total factor productivity. Capital deepening (lncapital) - expressed by the ratio of the fixed capital stock to the number of employees in urban units at the end of the year, and logarithms are taken here to eliminate the effect of heteroscedasticity. Per capita human capital level (lnedu) — the average wage level of employees is used to measure, and the nominal wage level of employees is fixed to 2010 through the urban consumer price index, and the logarithm is taken to eliminate the effect of heteroscedasticity. Generally, the higher the level of human capital, the higher the technological innovation ability of prefecture-level cities. At the same time, cities with higher levels of human capital reflect the advanced development of factor structure. Business environment (be)-expressed by the proportion of employees in non-public units in urban units. The higher the proportion of non-public sector employment in urban areas, the higher the level of market economy development of the prefecture-level city, the more active the market economy. To some extent, this reflects the good local business environment, which can attract a large number of employees and improve the regional employment rate. The higher the degree of marketization is, the higher the green total factor productivity is. Financial services (fd)-measured by the ratio of outstanding loans of financial institutions to GDP. The higher the loan balance of financial institutions is, the higher the financial service level of prefecture-level cities is, which can attract more enterprises, enhance economic vitality and provide a large number of jobs, thus promoting regional economic development. Whether the cities are located in key ecological function zones (kefz) or not, if the counties and districts located in key ecological function zones defined in the main functional Zone Planning of each province are excavated, the number of counties and districts located in key ecological function zones is equal to or more than half of the total number of cities, counties and districts, the cities will be listed as key ecological function cities. In this paper, thirteen key ecological function cities were identified, including seven in the upper river basin, five in the middle river basin, and one in the lower river basin. The high intensity of environmental regulation in key ecological function zones may inhibit the improvement of green total factor productivity. However, in the long run, it is beneficial to realize the advanced industrial structure and enhance green total factor productivity to prohibit the entry of high-pollution industries in key ecological function areas and restrict industrial development, and to vigorously develop the service industry by relying on rich cultural tourism resources.

\section{Results}

3.1. Measurement Results and Analysis of Environmental Regulation Intensity Index in the Yellow River Basin

The current situation analysis of pollutant emission indicators shows that all kinds of environmental pollutants show a downward trend, and environmental governance is increasing. The comprehensive intensity index of environmental regulation calculated by the entropy method is used as the result of environmental regulation. The spatial and temporal evolution trend of environmental regulation in prefecture-level cities and three 
major regions in the basin can be analyzed by selecting the initial, intermediate and ending years of this study.

Overall, as shown in Table 2, the intensity index of environmental regulation in the Yellow River Basin increases year by year, and the intensity of environmental regulation keeps strengthening. Only in 2017, there is a significant trend of weakening, but in 2018, it rapidly returns to strong environmental regulation. The provinces and autonomous regions in the Yellow River Basin have steadily increased their control and emphasis on ecological and environmental protection. The space on the middle and lower reaches of environmental regulation intensity presents certain gathered momentum of three areas of environmental regulation; the comprehensive strength index showed a trend of fluctuations rise, environmental regulation intensity is higher than the upstream downstream region and middle region, and the area of environmental regulation on comprehensive strength index plummeted in 2017. The reason lies in the decline of the utilization rate of industrial solid waste. Although the emission of environmental pollutants of prefecture-level cities in the basin is reduced and the pollution control capacity is constantly improved, the absolute value of pollutant emission remains high and the pressure of environmental protection is still great. Therefore, each region needs to strengthen environmental regulations to prevent it from becoming a "pollution haven".

Table 2. Comprehensive intensity index of environmental regulation in the Yellow River Basin, 2011-2019.

\begin{tabular}{ccccc}
\hline Year & Upper Reaches & Middle Reaches & Lower Reaches & Mean Value \\
\hline 2011 & 0.61 & 0.58 & 0.60 & 0.60 \\
2012 & 0.72 & 0.67 & 0.69 & 0.69 \\
2013 & 0.76 & 0.69 & 0.72 & 0.72 \\
2014 & 0.77 & 0.69 & 0.74 & 0.73 \\
2015 & 0.77 & 0.70 & 0.79 & 0.75 \\
2016 & 0.74 & 0.72 & 0.80 & 0.75 \\
2017 & 0.56 & 0.65 & 0.75 & 0.65 \\
2018 & 0.75 & 0.74 & 0.82 & 0.77 \\
2019 & 0.71 & 0.71 & 0.79 & 0.74 \\
Mean Value & 0.71 & 0.68 & 0.74 & 0.71 \\
\hline
\end{tabular}

According to the data provided in Table 3, we found that among the four provinces in the upper reaches of the Yellow River-Qinghai Province, Gansu Province, Inner Mongolia Autonomous Region, and Ningxia Hui Autonomous Region-Qinghai Province has the highest comprehensive intensity index of environmental regulation, followed by Gansu Province and Ningxia Autonomous Region, and Inner Mongolia Autonomous Region has the lowest intensity of environmental regulation. The comprehensive intensity index of environmental regulation in most prefecture-level cities in the upstream region shows a trend of first increase and then decrease, among which Lanzhou, Bayannur and Wuhai have continuously enhanced environmental regulation during this period. The comprehensive intensity index of environmental regulation in some cities has improved in 2015, indicating that the implementation of policies such as the "12th Five-Year" Comprehensive Work Programme for Energy Conservation and Emission Reduction has achieved remarkable results. The decline in the comprehensive intensity index of environmental regulation after 2015 is rooted in the decline in industrial solid waste utilization. In 2011, the prefecture-level cities with the highest comprehensive intensity index of environmental regulation were Xining City, Haidong City, Longnan City and Guyuan City. In 2015, they were Wuwei City, Guyuan City, Dingxi City and Haidong City. In 2019, they were Qingyang City, Lanzhou City, Wuwei City and Pingliang City. The intensity of environmental regulation in Haidong City, Guyuan City and Wuwei City has been high over the years. 
Table 3. Comprehensive intensity index of environmental regulation in cities in the upper reaches of the Yellow River Basin, 2011-2019.

\begin{tabular}{|c|c|c|c|c|c|c|c|c|c|}
\hline City & 2011 & 2012 & 2013 & 2014 & 2015 & 2016 & 2017 & 2018 & 2019 \\
\hline Lanzhou & 0.68 & 0.77 & 0.66 & 0.72 & 0.76 & 0.77 & 0.63 & 0.88 & 0.84 \\
\hline Baiyin & 0.49 & 0.63 & 0.78 & 0.74 & 0.73 & 0.72 & 0.54 & 0.86 & 0.70 \\
\hline Tianshui & 0.51 & 0.78 & 0.78 & 0.85 & 0.87 & 0.81 & 0.56 & 0.85 & 0.73 \\
\hline Wuwei & 0.66 & 0.82 & 0.82 & 0.91 & 0.94 & 0.93 & 0.55 & 0.84 & 0.82 \\
\hline Pingliang & 0.59 & 0.63 & 0.71 & 0.84 & 0.86 & 0.87 & 0.45 & 0.93 & 0.81 \\
\hline Qingyang & 0.59 & 0.87 & 0.93 & 0.90 & 0.82 & 0.73 & 0.66 & 0.95 & 0.85 \\
\hline Dingxi & 0.47 & 0.80 & 0.83 & 0.87 & 0.89 & 0.80 & 0.58 & 0.97 & 0.76 \\
\hline Longnan & 0.70 & 0.78 & 0.68 & 0.63 & 0.64 & 0.55 & 0.45 & 0.49 & 0.49 \\
\hline Hohhot & 0.63 & 0.65 & 0.66 & 0.56 & 0.63 & 0.63 & 0.49 & 0.49 & 0.57 \\
\hline Baotou & 0.53 & 0.49 & 0.48 & 0.54 & 0.59 & 0.61 & 0.51 & 0.56 & 0.58 \\
\hline Ulanqab & 0.57 & 0.70 & 0.83 & 0.78 & 0.77 & 0.80 & 0.49 & 0.74 & 0.68 \\
\hline Ordos & 0.62 & 0.59 & 0.51 & 0.51 & 0.53 & 0.68 & 0.44 & 0.68 & 0.72 \\
\hline Bayannaoer & 0.55 & 0.59 & 0.75 & 0.72 & 0.72 & 0.72 & 0.52 & 0.72 & 0.74 \\
\hline Wuhai & 0.57 & 0.67 & 0.72 & 0.65 & 0.70 & 0.72 & 0.56 & 0.69 & 0.71 \\
\hline Yinchuan & 0.67 & 0.67 & 0.75 & 0.81 & 0.83 & 0.81 & 0.62 & 0.68 & 0.65 \\
\hline Shizuishan & 0.64 & 0.71 & 0.77 & 0.79 & 0.74 & 0.49 & 0.53 & 0.43 & 0.59 \\
\hline Wuzhong & 0.66 & 0.73 & 0.76 & 0.75 & 0.78 & 0.62 & 0.57 & 0.80 & 0.62 \\
\hline Guyuan & 0.70 & 0.85 & 0.93 & 0.93 & 0.91 & 0.78 & 0.51 & 0.86 & 0.73 \\
\hline Zhongwei & 0.58 & 0.78 & 0.86 & 0.87 & 0.87 & 0.82 & 0.42 & 0.69 & 0.74 \\
\hline Xining & 0.76 & 0.86 & 0.79 & 0.81 & 0.79 & 0.90 & 0.85 & 0.81 & 0.74 \\
\hline Haidong & 0.73 & 0.84 & 0.87 & 0.88 & 0.89 & 0.82 & 0.76 & 0.76 & 0.80 \\
\hline
\end{tabular}

In Table 4, the comprehensive intensity index of environmental regulation in most prefecture-level cities in the middle reaches of the Yellow River Basin shows a continuous upward trend. The comprehensive intensity index of environmental regulation in Yangquan City, Yuncheng City and Yulin City is "U" type. The comprehensive intensity index of environmental regulation in Shuozhou City, Xinzhou City, Xi'an City, Tongchuan City, Baoji City, Xianyang City, Yan'an City and Shangluo City is an inverted ' $U$ ' type. The intensity of environmental regulation in most cities in Shaanxi Province has experienced a process of increasing first and then weakening. In 2011, the highest comprehensive intensity index of environmental regulation in the middle reaches of the Yellow River Basin was Weinan City, Tongchuan City, Yan'an City and Shuozhou City, and the lowest was Luoyang City, Linfen City, Xinzhou City and Zhengzhou City. In 2015, the highest comprehensive intensity index of environmental regulation was Tongchuan City, Yan'an City, Xi'an City and Shuozhou City, and the lowest was Yulin City, Yuncheng City, Changzhi City and Yangquan City. In 2019, the highest comprehensive intensity index of environmental regulation was Jiaozuo City, Zhengzhou City, Jinzhong City and Jincheng City. The lowest prefecture-level cities are Shangluo City, Lvliang City, Yan'an City and Baoji City. From the spatial distribution and proportion of cities with high comprehensive intensity index of environmental regulation, Shaanxi Province has strong environmental regulation in the middle reaches of the Yellow River Basin, followed by Shanxi Province.

Based on the data information in Table 5, it is not hard to find that the comprehensive intensity index of environmental regulation in the lower reaches of the Yellow River Basin is generally high, and there is a fluctuating upward trend. Among them, the comprehensive intensity index of environmental regulation in Kaifeng City, Anyang City, Jinan City, Zibo City, Dongying City, Jining City, Laiwu City, Binzhou City and Heze City is increasing. The intensity of environmental regulation in Hebi City, Xinxiang City, Puyang City, Tai'an City, Linyi City, Dezhou City and Liaocheng City first increases and then decreases. In 2011, the prefecture-level cities with the highest comprehensive intensity index of environmental regulation were Laiwu City, Puyang City, Hebi City and Dongying City, and the lowest were Jining City, Zibo City, Kaifeng City and Liaocheng City. In 2015, the prefecture-level cities with the highest comprehensive intensity index of environmental regulation were 
Hebi City, Puyang City, Dongying City and Kaifeng City, and the lowest were Zibo City, Binzhou City, Anyang City and Jining City. In 2019, the prefecture-level cities with the highest comprehensive intensity index of environmental regulation were Dongying, Laiwu, Puyang and Kaifeng, and the lowest were Linyi, Binzhou, Xinxiang and Anyang. The intensity of environmental regulation in Puyang City, Dongying City, Kaifeng City, Hebi City and Laiwu City has been high. Kaifeng City has the largest change in the intensity of environmental regulation, and Kaifeng City has finally squeezed into cities with high environmental regulation gradient.

Table 4. Comprehensive intensity index of environmental regulation of cities in the middle reaches of the Yellow River Basin, 2011-2019.

\begin{tabular}{cccccccccc}
\hline City & $\mathbf{2 0 1 1}$ & $\mathbf{2 0 1 2}$ & $\mathbf{2 0 1 3}$ & $\mathbf{2 0 1 4}$ & $\mathbf{2 0 1 5}$ & $\mathbf{2 0 1 6}$ & $\mathbf{2 0 1 7}$ & $\mathbf{2 0 1 8}$ & $\mathbf{2 0 1 9}$ \\
\hline Zhengzhou & 0.47 & 0.54 & 0.60 & 0.56 & 0.62 & 0.84 & 0.76 & 0.79 & 0.84 \\
Luoyang & 0.44 & 0.56 & 0.61 & 0.64 & 0.65 & 0.75 & 0.70 & 0.86 & 0.67 \\
Jiaozuo & 0.54 & 0.59 & 0.63 & 0.61 & 0.68 & 0.75 & 0.73 & 0.84 & 0.85 \\
Sanmenxia & 0.57 & 0.59 & 0.60 & 0.56 & 0.57 & 0.72 & 0.72 & 0.75 & 0.73 \\
Taiyuan & 0.62 & 0.68 & 0.69 & 0.67 & 0.72 & 0.60 & 0.71 & 0.78 & 0.72 \\
Yangquan & 0.62 & 0.66 & 0.63 & 0.58 & 0.57 & 0.50 & 0.64 & 0.58 & 0.69 \\
Changzhi & 0.47 & 0.50 & 0.50 & 0.53 & 0.56 & 0.62 & 0.58 & 0.71 \\
Jincheng & 0.63 & 0.72 & 0.72 & 0.73 & 0.76 & 0.68 & 0.70 & 0.74 & 0.71 \\
Shuozhou & 0.65 & 0.76 & 0.77 & 0.79 & 0.85 & 0.62 & 0.62 & 0.77 \\
Jinzhong & 0.51 & 0.65 & 0.69 & 0.73 & 0.79 & 0.83 & 0.75 & 0.95 & 0.63 \\
Yuncheng & 0.62 & 0.66 & 0.67 & 0.51 & 0.55 & 0.65 & 0.31 & 0.42 & 0.84 \\
Xinzhou & 0.46 & 0.63 & 0.66 & 0.69 & 0.68 & 0.66 & 0.54 & 0.81 & 0.68 \\
Linfen & 0.45 & 0.56 & 0.59 & 0.64 & 0.68 & 0.69 & 0.72 & 0.78 & 0.80 \\
Lv Liang & 0.49 & 0.70 & 0.61 & 0.67 & 0.58 & 0.54 & 0.59 & 0.58 & 0.59 \\
Xi'an & 0.58 & 0.70 & 0.76 & 0.80 & 0.86 & 0.86 & 0.78 & 0.83 \\
Tongchuan & 0.72 & 0.87 & 0.91 & 0.93 & 0.89 & 0.88 & 0.65 & 0.80 & 0.82 \\
Baoji & 0.63 & 0.73 & 0.75 & 0.76 & 0.67 & 0.75 & 0.69 & 0.81 \\
Xianyang & 0.53 & 0.76 & 0.79 & 0.83 & 0.84 & 0.80 & 0.82 & 0.76 & 0.63 \\
Weinan & 0.84 & 0.73 & 0.74 & 0.76 & 0.83 & 0.83 & 0.65 & 0.79 & 0.71 \\
Yan'an & 0.70 & 0.71 & 0.85 & 0.89 & 0.88 & 0.81 & 0.54 & 0.78 & 0.61 \\
Yulin & 0.57 & 0.73 & 0.57 & 0.52 & 0.54 & 0.66 & 0.53 & 0.56 & 0.66 \\
Shangluo & 0.60 & 0.69 & 0.73 & 0.69 & 0.66 & 0.73 & 0.54 & 0.64 & 0.45 \\
\hline
\end{tabular}

Table 5. Comprehensive intensity index of environmental regulation in the lower reaches of the Yellow River Basin, 2011-2019.

\begin{tabular}{cccccccccc}
\hline City & $\mathbf{2 0 1 1}$ & $\mathbf{2 0 1 2}$ & $\mathbf{2 0 1 3}$ & $\mathbf{2 0 1 4}$ & $\mathbf{2 0 1 5}$ & $\mathbf{2 0 1 6}$ & $\mathbf{2 0 1 7}$ & $\mathbf{2 0 1 8}$ & $\mathbf{2 0 1 9}$ \\
\hline Kaifeng & 0.51 & 0.65 & 0.69 & 0.75 & 0.87 & 0.91 & 0.97 & 0.93 & 0.86 \\
Anyang & 0.62 & 0.68 & 0.69 & 0.67 & 0.71 & 0.83 & 0.82 & 0.79 & 0.71 \\
Hebi & 0.67 & 0.78 & 0.83 & 0.84 & 0.89 & 0.88 & 0.93 & 0.95 & 0.85 \\
Xinxiang & 0.58 & 0.67 & 0.69 & 0.70 & 0.81 & 0.77 & 0.67 & 0.84 & 0.70 \\
Puyang & 0.71 & 0.78 & 0.82 & 0.87 & 0.88 & 0.88 & 0.72 & 0.96 & 0.87 \\
Jinan & 0.62 & 0.72 & 0.73 & 0.78 & 0.79 & 0.84 & 0.68 & 0.81 & 0.83 \\
Zibo & 0.49 & 0.49 & 0.51 & 0.52 & 0.64 & 0.67 & 0.58 & 0.69 & 0.72 \\
Dongying & 0.66 & 0.73 & 0.77 & 0.83 & 0.88 & 0.87 & 0.86 & 0.87 & 0.89 \\
Jining & 0.40 & 0.54 & 0.57 & 0.62 & 0.72 & 0.80 & 0.62 & 0.77 & 0.81 \\
Taian & 0.66 & 0.75 & 0.79 & 0.81 & 0.87 & 0.89 & 0.92 & 0.93 & 0.86 \\
Laiwu & 0.72 & 0.79 & 0.84 & 0.81 & 0.77 & 0.74 & 0.69 & 0.82 & 0.89 \\
Linyi & 0.63 & 0.67 & 0.68 & 0.70 & 0.73 & 0.76 & 0.83 & 0.72 & 0.66 \\
Dezhou & 0.66 & 0.72 & 0.74 & 0.78 & 0.83 & 0.80 & 0.68 & 0.84 & 0.79 \\
Liaocheng & 0.56 & 0.72 & 0.84 & 0.78 & 0.84 & 0.84 & 0.73 & 0.77 & 0.73 \\
Binzhou & 0.59 & 0.60 & 0.61 & 0.57 & 0.66 & 0.53 & 0.55 & 0.56 & 0.69 \\
Heze & 0.61 & 0.71 & 0.76 & 0.77 & 0.81 & 0.84 & 0.72 & 0.90 & 0.85 \\
\hline
\end{tabular}




\subsection{Calculation and Analysis of GTFP in the Yellow River Basin}

\subsubsection{Spatial-Temporal Evolution Trend and Regional Difference Analysis of GTFP}

From Table 6, the overall GTFP of the Yellow River Basin is only higher than 1 in 2012, 2016, 2017 and 2018, and the average GTFP in other years is lower than 1, showing a certain economic recession. From the Figure 1, the overall GTFP of the Yellow River Basin shows a trend of first decreasing and then increasing, and the average GTFP was the highest in 2018 and the lowest in 2019.

Table 6. Green total factor productivity (GTFP) of provinces in the Yellow River Basin from 2011 to 2019.

\begin{tabular}{ccccccccccc}
\hline Province & $\mathbf{2 0 1 1}$ & $\mathbf{2 0 1 2}$ & $\mathbf{2 0 1 3}$ & $\mathbf{2 0 1 4}$ & $\mathbf{2 0 1 5}$ & $\mathbf{2 0 1 6}$ & $\mathbf{2 0 1 7}$ & $\mathbf{2 0 1 8}$ & $\mathbf{2 0 1 9}$ \\
\hline Gansu & 0.99 & 0.96 & 0.96 & 0.97 & 0.96 & 1.01 & 0.99 & 1.01 & 0.89 \\
$\quad$ Henan & 1.00 & 1.04 & 0.97 & 0.98 & 0.99 & 1.09 & 0.99 & 1.05 & 0.68 \\
$\begin{array}{c}\text { Inner Mongolia } \\
\text { Autonomous }\end{array}$ & 0.99 & 1.01 & 0.96 & 0.94 & 0.95 & 1.14 & 0.98 & 1.05 & 1.07 \\
$\quad \begin{array}{l}\text { Region } \\
\text { Ningxia Hui }\end{array}$ & & & & & & & & & \\
Autonomous & 0.97 & 0.99 & 0.92 & 0.99 & 0.97 & 1.00 & 1.02 & 1.02 & 0.76 \\
$\quad$ Region & & & & & & & & \\
$\quad$ Qinghai & 0.99 & 1.00 & 0.96 & 1.03 & 1.00 & 0.99 & 1.02 & 1.13 & 0.89 \\
$\quad$ Shandong & 1.02 & 0.99 & 0.93 & 0.97 & 0.96 & 1.01 & 1.02 & 1.04 & 0.87 \\
$\quad$ Shanxi & 1.01 & 0.97 & 0.95 & 1.03 & 0.89 & 1.06 & 1.05 & 1.07 & 0.90 \\
$\quad$ Shaanxi & 0.94 & 1.07 & 0.96 & 0.97 & 1.02 & 1.03 & 0.96 & 1.01 & 0.99 \\
Total Basin & 0.99 & 1.00 & 0.95 & 0.98 & 0.97 & 1.04 & 1.00 & 1.05 & 0.88 \\
\hline
\end{tabular}

By region, the distribution of GTFP in the upper and middle reaches of China is discrete and varies greatly from year to year, indicating that the development of prefecturelevel cities in the upper and middle reaches of China is unbalanced. GTFP showed a downward trend after 2011, but the downward trend was reversed and an increasing trend emerged after 2015. The distribution of GTFP in the downstream area was concentrated with little change, showing a trend of decline first and then rise. In 2013, GTFP reached a low point, which was greatly affected by the ten policies of the atmosphere, and the economic development experienced a temporary decline, but it was quickly adjusted.

From the perspective of provinces, there are great differences in GTFP among provinces. GTFP in Gansu Province increased only in 2016 and 2018, and GTFP in other years was lower than 1. The growth trend of GTFP in Henan Province is unstable, and it fell from 1.05 to 0.68 in 2018-2019. The GTFP of Inner Mongolia Autonomous Region was greater than 1 in 2012, 2016, 2018 and 2019, and fluctuated in other years. The GTFP in Ningxia Hui Autonomous Region has been lower than 1 for a long time, but it improved in 2016. The GTFP of Qinghai Province fluctuates around 1 each year, and the overall level is high. Shandong Province is a province with a high degree of development in the Yellow River Basin, and its GTFP is higher than most provinces in each year. GTFP in Shanxi Province declined in the alternate period of '12th Five-Year' and '13th Five-Year'. Shaanxi Province is a major energy province, and the GTFP showed a trend of rising first, then falling and rising again. Overall, in 2019, the GTFP of each province in the whole basin decreased, and the overall economic situation was not good.

\subsubsection{Decomposition and Driving Effect Analysis of GTFP}

The GTFP is decomposed and its driving factors are investigated to provide path guidance for the improvement of GTFP. The cities in the Yellow River Basin are divided into the upper, middle and lower reaches to explore the green economic growth in each basin. GML index represents the GTFP; GEC and GTC representglobal efficiency change index and global technological change Index, respectively.

As shown in Figure 2, the improvement of GTFP is driven by the scale efficiency of green technology. From the perspective of prefecture-level cities, most cities have 
improved GTFP; only Yinchuan and Zhongwei have declined, which is mainly caused by the deterioration of green technical efficiency. The growth of GTFP in most prefecture-level cities in the upper reaches is caused by the improvement of green technical efficiency, so green technical efficiency has made great contributions to the economic development of the upper reaches.
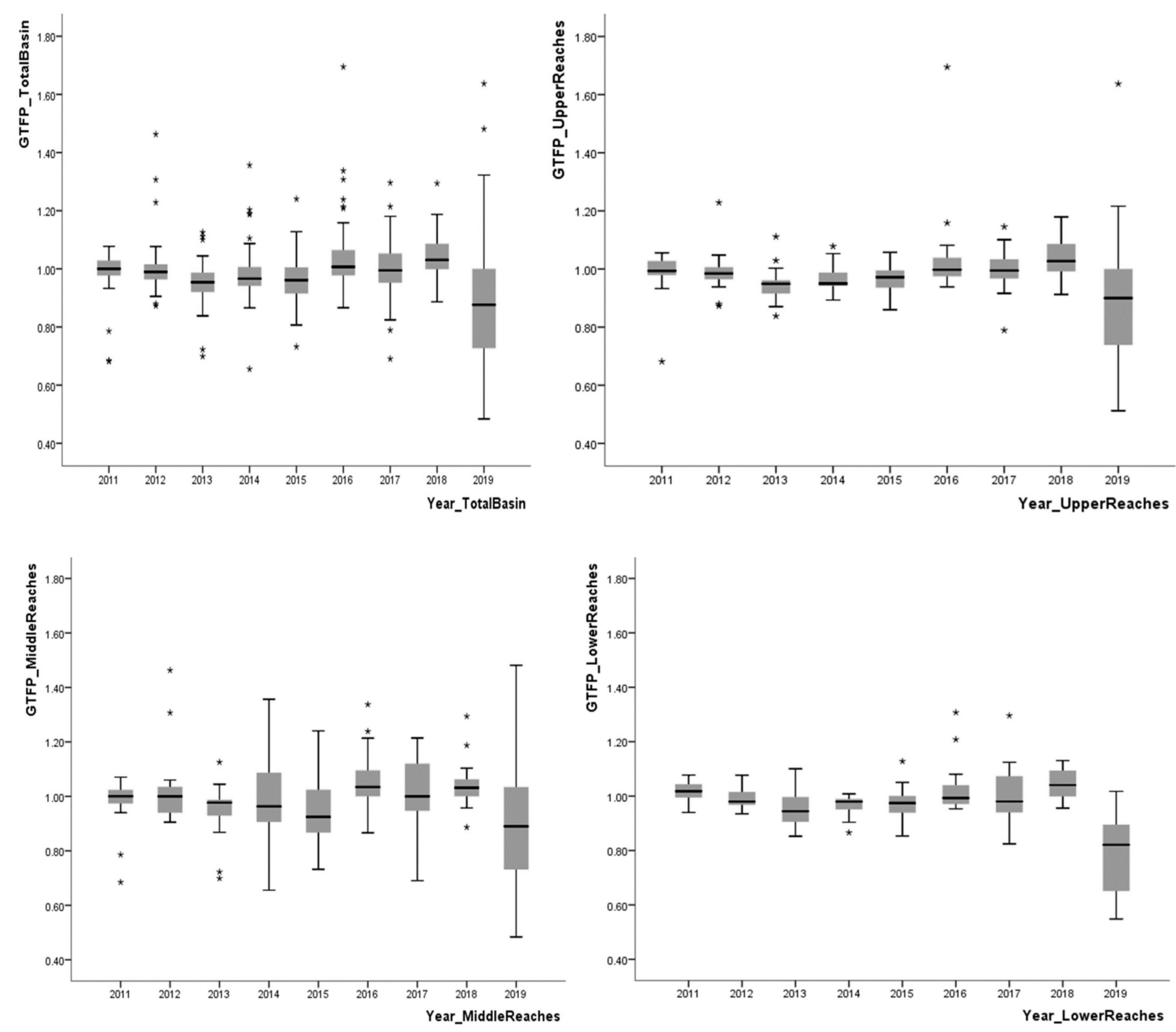

Figure 1. Boxplot of GTFP changes in the three regions of the Yellow River Basin from 2011 to 2019. Note: In Figure 1, the uppermost transverse line represents the upper bound, and the lowermost transverse line represents the lower bound. The upper edge of the box represents a third of the quartile, and the lower edge represents a quarter of the quartile. The middle transverse line represents the mean value, and its discrete solid point represents the outliers. 


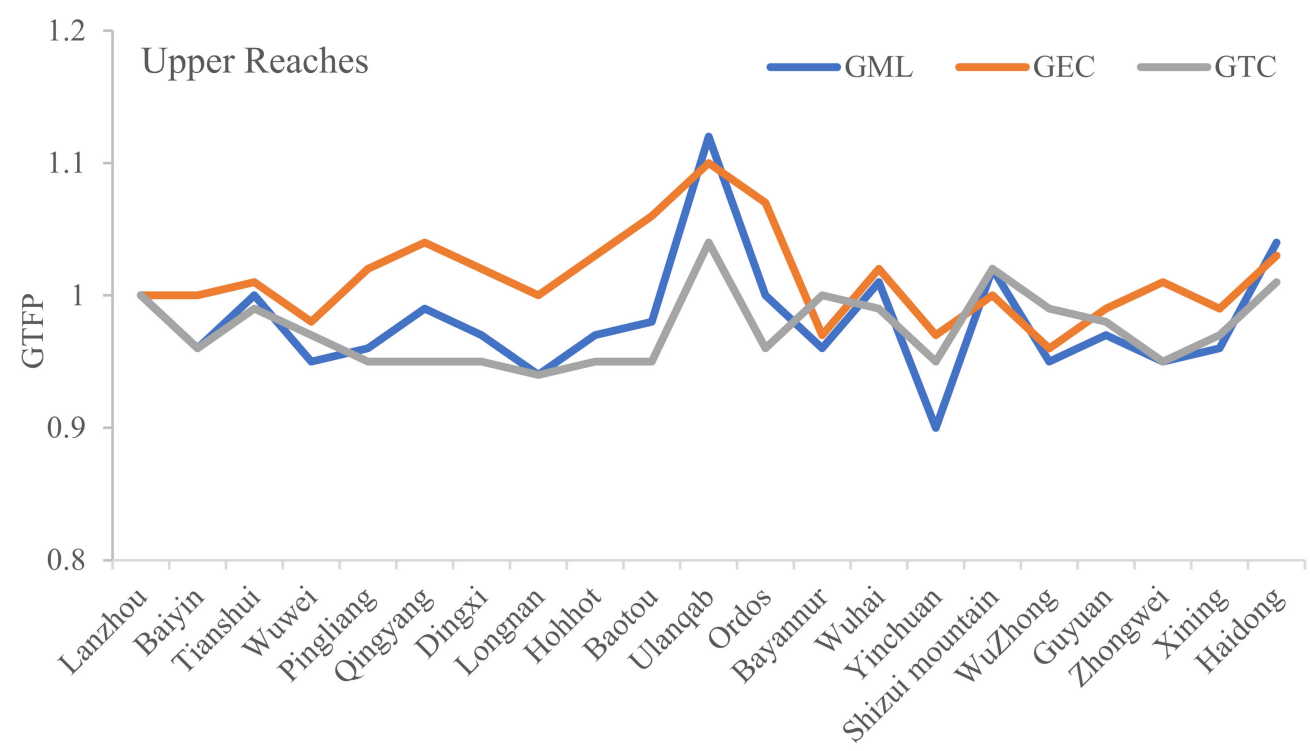

Figure 2. Average GTFP index and decomposition of cities in the upper reaches of the Yellow River Basin from 2011 to 2019. Global Malmquist Luenberger (GML); Global Efficiency Change Index (GEC); Global Technical Change Index (GTC).

From the overall situation of the middle reaches of the Yellow River Basin, as shown in Figure 3, the average GTFP is the highest in the three basins, showing an increasing trend, in which the technological progress index decreases and the technological efficiency leads to the increase of GTFP. At the municipal level, most cities achieved green economic growth, with individual cities growing faster than provincial capitals. The cities with low GTFP in the middle reaches are mostly located in Shanxi Province, which can be seen that the development process of green economy in Shanxi Province is slow. The green technical efficiency index of most prefecture-level cities is greater than 1, indicating that the improvement of green technical efficiency is the source of economic growth in the middle reaches.

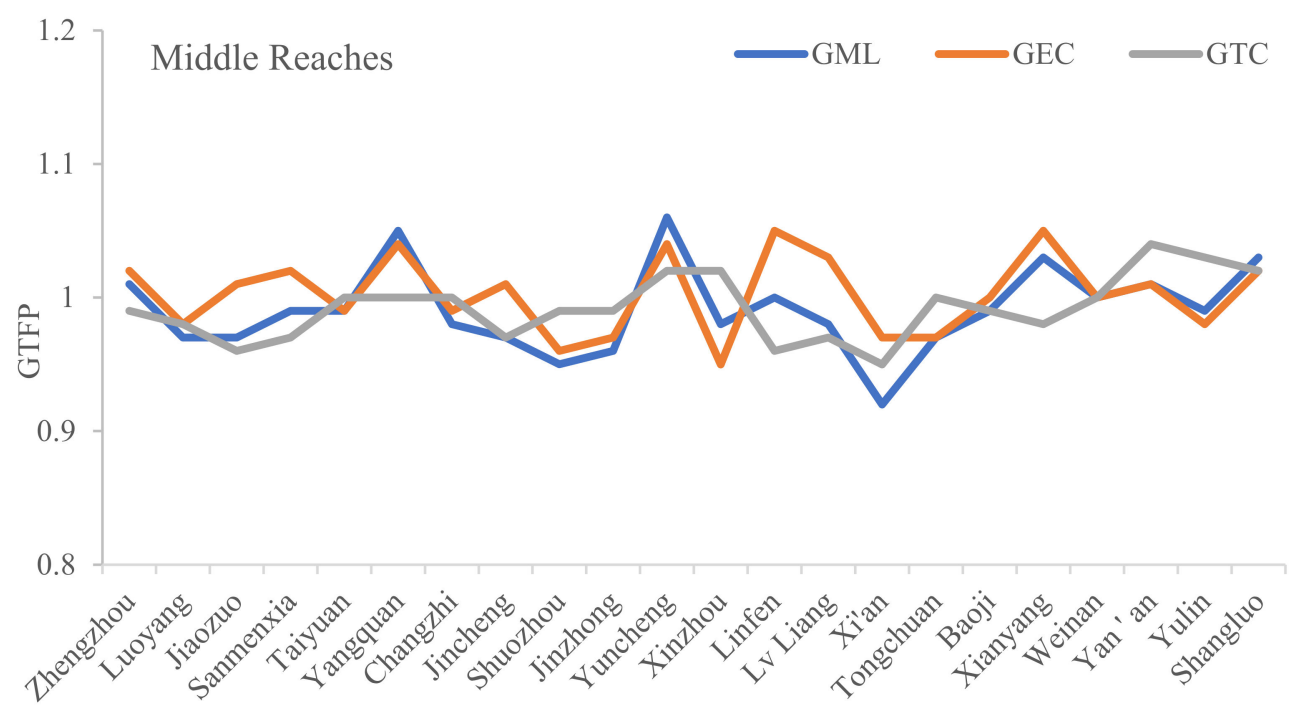

Figure 3. Average GTFP index and decomposition of cities in the middle reaches of the Yellow River Basin, 2011-2019.

As shown in Figure 4, the increase in GTFP in the lower reaches of the Yellow River Basin is mainly caused by green technical efficiency. The green technology progress index of 
most prefecture-level cities is not more than 1, and only Kaifeng, Jining, Linyi and Dezhou are more than 1 . The technical efficiency index is generally greater than the technical progress index, indicating that the GTFP in the downstream region is also driven by the improvement of technical efficiency.

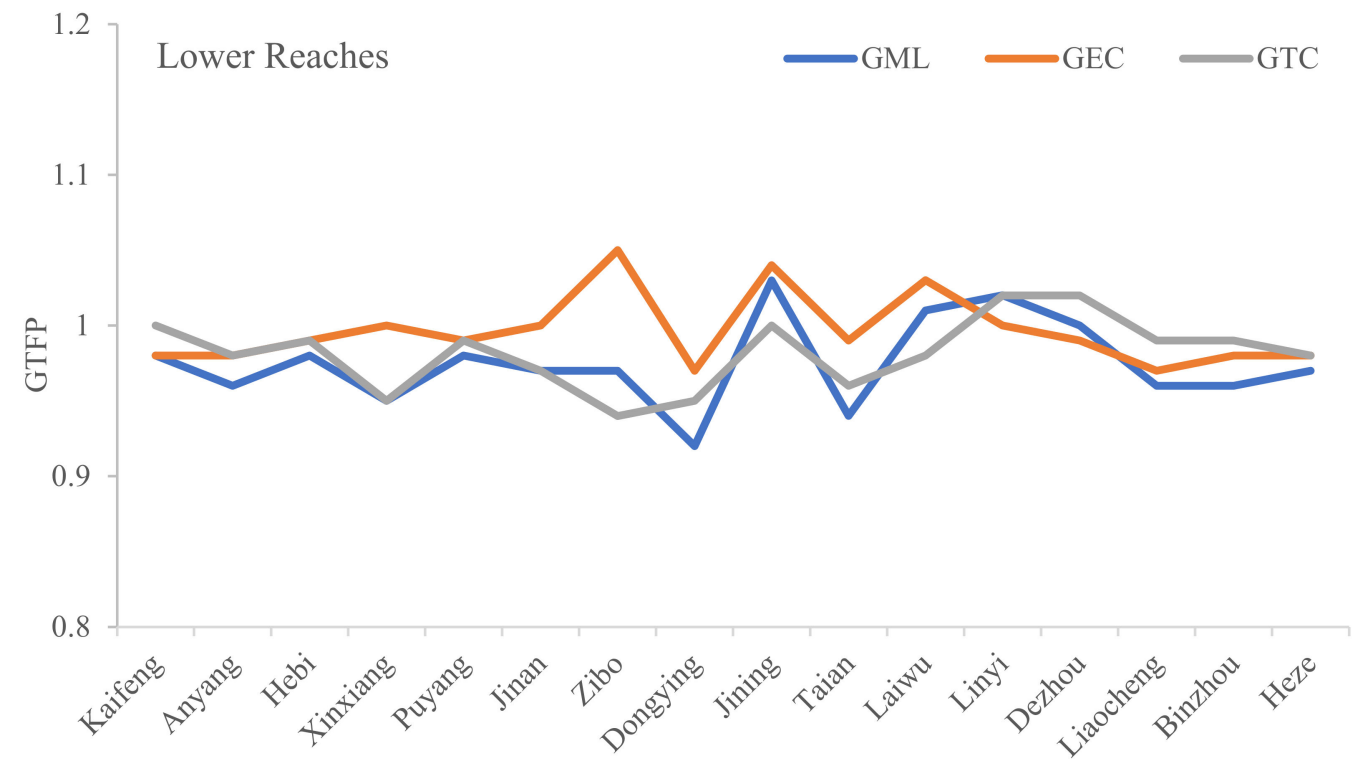

Figure 4. Average GTFP and decomposition of cities in the lower reaches of Yellow River Basin, 2011-2019.

\subsection{Empirical Analysis of the Impact of Environmental Regulation on GTFP in the Yellow} River Basin

The impact of environmental regulation on GTFP has direct and indirect effects. Direct benefits mainly include environmental cost effect and entry barrier effect. Among them, environmental cost effect has a negative impact on GTFP in theory, while the impact of entry barrier effect on GTFP is uncertain. The indirect effects mainly include technological innovation effect, factor structure effect, industrial structure effect, and FDI pollution haven effect. Among them, factor structure effect, industrial structure effect and FDI pollution haven effect have a promoting effect on the improvement of GTFP, while technological innovation effect has uncertainty on its impact. Based on the influence mechanism of environmental regulation and GTFP, the following model is constructed and empirical analysis is carried out. Descriptive statistics for Tobit model variables are shown in Table 7.

Table 7. Descriptive statistics of variables.

\begin{tabular}{cccccc}
\hline Region & Variable & Mean Value & Standard Deviation & Minimum Value & Maximum Value \\
\hline Total Basin & GTFP & 0.9332 & 0.1841 & 0.3584 & 1.9945 \\
& er & 0.7094 & 0.1228 & 0.3053 & 0.9694 \\
& tec & 0.0099 & 0.0078 & 0.0000 & 0.0467 \\
& lncapital & 4.8371 & 0.4429 & 3.7634 & 6.1299 \\
& lnedu & 10.7746 & 0.2523 & 8.4190 & 11.3506 \\
& be & 0.4908 & 0.1831 & 0.0240 & 0.9329 \\
& fd & 1.0766 & 0.8863 & 0.2334 & 9.6221 \\
\hline
\end{tabular}


Table 7. Cont.

\begin{tabular}{cccccc}
\hline Region & Variable & Mean Value & Standard Deviation & Minimum Value & Maximum Value \\
\hline Upper Reaches & GTFP & 0.9123 & 0.1851 & 0.3584 & 1.9945 \\
& er & 0.7097 & 0.1311 & 0.4250 & 0.9668 \\
& tec & 0.0066 & 0.0049 & 0.0000 & 0.0272 \\
& lncapital & 4.9925 & 0.4862 & 3.7963 & 6.1299 \\
& lnedu & 10.8257 & 0.2887 & 8.4190 & 11.3506 \\
Middle Reaches & be & 0.3765 & 0.1599 & 0.0240 & 0.7152 \\
& fd & 1.3927 & 1.0334 & 0.3561 & 9.6221 \\
& GTFP & 0.9481 & 0.1980 & 0.4530 & 1.6233 \\
& er & 0.6824 & 0.1145 & 0.3053 & 0.9512 \\
& tec & 0.0103 & 0.0087 & 0.0000 & 0.0462 \\
& lncapital & 4.7134 & 0.4092 & 3.7634 & 5.9315 \\
& lnedu & 10.7579 & 0.2027 & 10.2585 & 11.3249 \\
& be & 0.4845 & 0.1483 & 0.0470 & 0.7673 \\
& fd & 1.0168 & 0.9208 & 0.2334 & 7.4502 \\
& GTFP & 0.9402 & 0.1601 & 0.4623 & 1.2780 \\
& er & 0.7460 & 0.1136 & 0.4025 & 0.9694 \\
& tec & 0.0139 & 0.0076 & 0.0003 & 0.0467 \\
& lncapital & 4.8032 & 0.3624 & 3.9970 & 5.7923 \\
& lnedu & 10.7304 & 0.2528 & 10.1445 & 0.2696 \\
& be & 0.6496 & 0.1326 & 0.2870 & 0.9329 \\
& fd & 0.7440 & 0.3019 & & 1.9561 \\
\hline
\end{tabular}

\subsubsection{Empirical Results and Analysis}

Through empirical research, this paper analyzes the impact of environmental regulation and other factors on GTFP in the whole basin, upper reaches, middle reaches and lower reaches of the Yellow River Basin.

In Table 8, the panel Tobit model regression results show that the impact coefficient of environmental regulation on GTFP in the whole basin, upstream, middle and downstream areas is positive, and environmental regulation can promote the growth of GTFP in the basin. The Yellow River Basin breaks through the cost effect brought by environmental regulation and triggers technological innovation, thereby enhancing GTFP. Due to the dual pressures of fragile ecological environment and overload of resources and environment in the Yellow River Basin, the contradiction between protection and development is highlighted. Strict environmental access policies restrict the entry of high-pollution industries, and higher barriers to entry avoid the watershed becoming a pollution haven, which is conducive to the improvement of GTFP. The upstream region is rich in energy reserves and has formed a core industrial chain of petrochemical industry, equipment manufacturing, new materials and new energy. The middle reaches of the region take advantage of traditional industries to actively transform and develop high-end equipment manufacturing and other emerging industries. Downstream areas vigorously develop modern agriculture and services, and strive to promote bio-pharmaceutical, energy conservation and environmental protection, information technology and other industries. The improvement of environmental regulation makes the industrial structure advanced. The adjustment of industrial structure and technological progress have promoted the gradual rationalization of river basin factor structure, which is helpful to realize the coordinated development of river basin ecology and economy. The impact coefficient of science and technology input on GTFP in the Yellow River Basin and the middle and lower reaches is positive, and the impact coefficient on the upstream region is negative, indicating that the upstream region should accelerate the transformation of science and technology into practical results. The influence coefficient of capital deepening on GTFP in the whole Yellow River Basin and the upper and middle reaches is positive, indicating that the adjustment of capital structure in the basin promotes GTFP. However, the impact coefficient on the downstream region is negative. The downstream region should pay attention to adjusting the capital structure and solving 
the amount of redundant capital to transform it into productivity. The influence coefficient of per capita human capital on GTFP in the Yellow River Basin and the upper, middle and lower reaches is negative, indicating that the increase in wages of employees has increased the operating costs of enterprises, squeezed out the production investment and technological innovation investment of enterprises, and inhibited the improvement of GTFP to some extent. The influence coefficient of business environment on GTFP in the Yellow River Basin and the downstream area is positive. A good business environment and a booming market economy can improve regional GTFP, while the coefficient of business environment on GTFP in the upper and middle reaches is negative, indicating that the upper and middle reaches need to improve the business environment and attract capital inflows. The impact coefficient of financial service level on upstream, middle and downstream regions is positive, indicating that the improvement of financial service level can improve the GTFP of the basin to a certain extent. However, the influence coefficient on the GTFP of the whole basin is negative, indicating that the overall economic development of the Yellow River Basin is not high, the government has high financial debt, and financial deficits often occur. Although financial institutions increase lending to small and medium-sized enterprises, they are still unable to improve the productivity of the whole region. Whether it is in the key ecological function areas has a great difference in the impact of GTFP, and the impact coefficient on the whole basin and upstream and downstream areas is negative, indicating that the increase of ecological protection restricts regional economic development, thereby reducing GTFP. The influence coefficient of GTFP in the middle reaches is positive. For the middle reaches, economic development and ecological protection can effectively improve GTFP and realize the coordinated development of economy and environment.

Table 8. Panel Tobit model regression results.

\begin{tabular}{ccccc}
\hline Variable & Total Basin & Upper Reaches & Middle Reaches & Lower Reaches \\
\hline er & $0.0302^{* * *}$ & $0.1181^{* *}$ & $0.1404^{* * *}$ & $0.1600^{*}$ \\
& $(0.0747)$ & $(0.1301)$ & $(0.1273)$ & $(0.1640)$ \\
tec & $1.1505^{* * *}$ & $-9.5087^{* * *}$ & $1.1523^{*}$ & $9.5850^{*}$ \\
& $(1.5297)$ & $(3.7574)$ & $(1.9562)$ & $(2.8713)$ \\
lncapital & 0.0292 & $0.0817^{* * *}$ & 0.0617 & $-0.0588^{* * *}$ \\
& $(0.0253)$ & $(0.0373)$ & $(0.0438)$ & $(0.0782)$ \\
lnedu & $-0.2411^{* * *}$ & $-0.0424^{* * *}$ & $-0.7359^{* * *}$ & $-0.3664^{* * *}$ \\
& $(0.0493)$ & $(0.0616)$ & $(0.1243)$ & $(0.1440)$ \\
be & $0.0074^{* * *}$ & $-0.0252^{* * *}$ & $-0.0430^{* * * *}$ & $0.0998^{* * *}$ \\
& $(0.0674)$ & $(0.1381)$ & $(0.1174)$ & $(0.1539)$ \\
fd & -0.0027 & $0.0025^{* * *}$ & 0.0532 & $0.1027^{*}$ \\
& $(0.0107)$ & $(0.0149)$ & $(0.0294)$ & $(0.0754)$ \\
kefz & -0.0221 & $-0.0240^{*}$ & 0.0081 & $-0.0699 *$ \\
& $(0.0220)$ & $(0.0340)$ & $(0.0343)$ & $(0.0673)$ \\
\hline
\end{tabular}

Note: The values in small brackets are standard errors; robust standard errors in parentheses. ${ }^{* * *} p<0.01$, ** $p<0.05, * p<0.1$.

\subsubsection{Robustness Test}

Robustness tests are generally carried out by replacing some key variables and reselecting estimation methods. If the re-estimation results are not significantly different, the robustness of the research results is proved. The key variables in this paper are mainly reflected in the selection of environmental regulation variables. The intensity of urban environmental regulation is measured by the single index method or the comprehensive index method. In this paper, the entropy method is used to calculate the comprehensive intensity index of the environment as the variable of environmental regulation. In order to verify the reliability of the above empirical results, the environmental regulation variables are adjusted. The single indicator of average PM2.5 concentration in prefecture-level cities is used to measure the intensity of environmental regulation in prefecture-level cities. Since the average concentration of PM2.5 is affected by many factors, its diffusion is greatly affected by natural factors such as regional wind speed and rainfall. The greater 
the average concentration of PM2.5 is, the worse the diffusion conditions are, and it will be subject to stronger human environmental regulation. In this paper, the average concentration of PM2.5 in each prefecture-level city from 2011 to 2019 is used as the environmental regulation intensity index in the robustness test. This index is derived from the atmospheric composition analysis group of the Dalhousie University. It is the average concentration of PM2.5 in different administrative levels in China estimated by the research team using NASA satellite and ground monitoring station data. This paper extracts the required data of 59 prefecture-level cities [30]. After replacing the intensity index of environmental regulation, the panel Tobit model is used again for estimation, as shown in Table 9. Although the coefficient values of variables have changed, the influence directions of key variables are consistent, which proves that the research results of this paper have strong robustness.

Table 9. Robustness test.

\begin{tabular}{ccccc}
\hline Variable & Total Basin & Upper Reaches & Middle Reaches & Lower Reaches \\
\hline er & $0.0020^{*}$ & $0.0050^{* *}$ & $0.0015^{*}$ & $0.0021^{* * *}$ \\
& $(0.0007)$ & $(0.0017)$ & $(0.0012)$ & $(0.0015)$ \\
tec & $0.1142^{* * *}$ & $-4.6535^{* * *}$ & 0.5569 & 9.7887 \\
& $(1.5509)$ & $(3.4965)$ & $(1.9636)$ & $(2.4192)$ \\
Incapital & 0.0568 & $0.0710^{* * *}$ & 0.0761 & $-0.0638^{* * *}$ \\
& $(0.0268)$ & $(0.0395)$ & $(0.0444)$ & $(0.0736)$ \\
lnedu & $-0.1916^{* * *}$ & $-0.0591^{* * *}$ & $-0.5939 * * *$ & $-0.4382^{* * *}$ \\
& $(0.0515)$ & $(0.0607)$ & $(0.1486)$ & $(0.1534)$ \\
be & $-0.0703^{* * *}$ & $-0.2084^{* * *}$ & $-0.1103 * * *$ & $0.0186^{* * *}$ \\
& $(0.0717)$ & $(0.1304)$ & $(0.1280)$ & $(0.1290)$ \\
fd & 0.0015 & -0.0237 & 0.0452 & $0.1110^{*}$ \\
& $(0.0108)$ & $(0.0139)$ & $(0.0280)$ & $(0.0752)$ \\
kefz & -0.0152 & $-0.0111^{*}$ & 0.0017 & $-0.0619 *$ \\
& $(0.0220)$ & $(0.0366)$ & $(0.0335)$ & $(0.0633)$ \\
\hline
\end{tabular}

Note: The values in small brackets are standard errors; robust standard errors in parentheses. ${ }^{* * *} p<0.01$ $* *<0.05, * p<0.1$.

\section{Conclusions and Discussion}

In this paper, the entropy method and the DEA-SBM model are used to calculate the comprehensive intensity index of environmental regulation and the green TFP of 59 prefecture-level cities in the Yellow River Basin. This paper mainly draws the following conclusions: Firstly, the intensity of environmental regulation in the Yellow River Basin has increased year by year, showing strong regional heterogeneity. The intensity of environmental regulation in the lower reaches of the Yellow River Basin is significantly higher than that in the middle and upper reaches. The environmental regulation intensity of most prefecture-level cities in the upper reaches has experienced a process of first increasing and then decreasing. The environmental regulation intensity of most prefecture-level cities in the middle reaches has increased year by year. The environmental regulation intensity of prefecture-level cities in the lower reaches is generally high, and there is a fluctuating upward trend. Secondly, the overall GTFP in the Yellow River Basin shows an upward trend, and the growth of GTFP is mainly driven by the improvement of green technical efficiency. The GTFP in the upper and middle reaches fluctuated greatly, and experienced a recession in 2013 and 2015. However, it increased rapidly after 2017. The GTFP in the lower reaches of the Yellow River Basin remained stable from 2012 to 2018. There was no growth trend, only slightly increased after 2017. Finally, environmental regulation promotes the growth of GTFP in the whole Yellow River Basin and the upper, middle and lower reaches. The "Porter Hypothesis" is verified in the Yellow River Basin, and the breakthrough of environmental regulation follows the cost effect. Through the effect of technological innovation, environmental regulation encourages enterprises to adopt advanced technology, and improves the efficiency of technology use, to promote the formation of a virtuous cycle of environmental production in the basin. The application of environmental regulation has 
derived green consumption demand and green investment demand, which have an impact on the factor structure and industrial structure in the basin, making the factor structure tend to be rationalized and the industrial structure green and advanced, thus improving the green total factor production.

Green development is the key to ecological protection and high-quality development in the Yellow River Basin. Strict environmental control over the Yellow River Basin can make the Yellow River Basin become the undertaker of industrial transfer and avoid becoming a "pollution haven". Based on the heterogeneity of watershed ecological environment, it is necessary to formulate more flexible environmental regulation policies according to the whole watershed and different regions in the upper, middle and lower reaches, select appropriate environmental regulation scales and a variety of environmental regulation tools, and reduce the proportion of traditional factors and improve resource utilization efficiency through human capital investment and technological innovation. The government should further improve the incentive policy of enterprise innovation, reduce some taxes or implement innovation subsidies for industrial enterprises, help industrial enterprises to reduce innovation costs, constantly optimize the business environment, attract high-tech enterprises to enter, improve the ability of financial services in technological innovation and achievement transformation, and optimize local industrial structure, to improve GTFP.

Green economic growth in the Yellow River Basin and, consistent with most studies, technical efficiency, drives green total factor economic growth [31,32]. However, there are some differences in the trend of GTFP compared with the national level. The national provincial level rose year by year [33]; the Yellow River Basin showed a trend of first decline and then rise, accompanied by more obvious spatial differences. The main reason is that, compared with other regions, the Yellow River Basin has special innate natural conditions and acquired social function positioning, and is subject to strong environmental regulations, so the green total factors fluctuate greatly. The conclusion that environmental regulation significantly promotes the growth of GTFP is consistent with most scholars' research, which verifies the establishment of Porter's hypothesis from the perspective of productivity, indicating that pollution control and the improvement of productivity may become a win-win situation [34,35]. However, a considerable number of studies have shown that the high-intensity environmental regulation has an inhibitory effect on industrial GTFP [36,37]. The reason for this difference is that there is a time lag effect of environmental regulation on promoting GTFP, and the rationality of environmental regulation affects its effect on GTFP [38]. The formal environmental regulation discussed in this paper has a positive promoting effect on green total factor productivity, but the informal environmental regulation related to residents' environmental awareness sometimes has a restraining effect on GTFP growth due to the 'technological rebound' induced by technological innovation, that is, the stimulation of technological innovation on enterprise economic growth induces the increase of enterprise technical personnel and energy investment [39]. Environmental regulation can also promote economic development through the upgrading effect of industrial structure. The differences in regional development stages, especially the differences in regional industrial diversification, industrial technology composition and industrial agglomeration characteristics caused by the adjustment of industrial spatial layout, determine the specific selection of environmental regulation methods, thus having different impacts on the growth of green total factor productivity.

Due to the serious lack of data in some prefecture-level administrative regions, to avoid the error of research results, the eliminated prefecture-level administrative regions have an important strategic position in the Yellow River Basin, and this paper has not studied them. At the same time, the quality of the missing data of each index is uneven. Although the average value or linear interpolation method in the past two years is used to supplement, it will affect the research results and lead to errors. At present, there are great differences in the selection of indicators to evaluate the intensity of urban environmental regulation. In this paper, the comprehensive intensity index of environmental regulation is used as a standard to measure environmental regulation, which has certain limitations. 
However, the data collection of prefecture-level cities is difficult. At present, most scholars use this method to evaluate, and there is room for improvement in the calculation of environmental regulation intensity. In future research, we can expand the research object, extend the research cycle, and adopt more suitable measurement indicators for multi-scale dynamic analysis.

Author Contributions: Conceptualization, J.M. and C.L.; methodology, Q.W., M.Z. and J.M.; formal analysis, Q.W. and M.Z.; investigation, Q.W., M.Z., J.M. and C.L.; writing—original draft preparation, J.M. and Q.W.; writing-review and editing, J.M. and C.L. All authors have read and agreed to the published version of the manuscript.

Funding: This research was funded by the National Social Science Foundation Western Region Project (20XJL008), and the Fundamental Research Funds for the Central Universities (21lzujbkydx044, 2020jbkyjc002).

Institutional Review Board Statement: Not applicable.

Informed Consent Statement: Not applicable.

Data Availability Statement: The data used to support the findings of this study are available from the corresponding author upon reasonable request.

Acknowledgments: Project of Excellent Graduate Student "Innovation Star" of Gansu Provincial Education Department (2021CXZX-054) is acknowledged for financial support.

Conflicts of Interest: The authors declare no conflict of interest.

\section{References}

1. Zhang, Y.; Zhu, F.; He, L. Definition, Classification and Evolution of Environmental Regulation. China Popul. Resour. Environ. 2009, 19, 85-90.

2. Francesco, T.; Fabio, I.; Marco, F. The effect of environmental regulation on firms' competitive performance: The case of the building \& construction sector in some EU regions. J. Environ. Manag. 2011, 92, 2136-2144.

3. Zhang, C.; Lu, Y.; Guo, L.; Yu, T. The Intensity of Environmental Regulation and Technological Progress of Production. Econ. Res. 2011, 46, 113-124.

4. Hu, Y.L.; Sun, H.R. The Effects of Environmental Regulation on Enterprise Performance: Current Research and Literature Review. Ecoeconomy 2016, 32, 94-98.

5. Lanoie, P.; Patry, M.; Lajeunesse, R. Environmental regulation and productivity: Testing the porter hypothesis. J. Product. Anal. 2008, 30, 121-128. [CrossRef]

6. Porter, M.E.; Van der Linde, C. Toward a New Conception of the Environment-Competitiveness Relationship. J. Econ. Perspect. 1995, 9, 97-118. [CrossRef]

7. Hu, J.; Zhao, W.; Lian, Y. Environmental Regulation, Foreign Direct Investment and Green Technological Progress-Evidence from Chinese Manufacturing Industries. Int. J. Environ. Res. Public Health 2018, 15, 221. [CrossRef] [PubMed]

8. Zhang, J.; Gon, E.; Sun, Y. How will environmental regulation effect TFP of manufacturing in Yangtze River Economic Belt? Stud. Sci. Sci. 2019, 37, 1558-1569.

9. Berman, E.; Bui, L. Environmental Regulation and Productivity: Evidence from Oil Refineries. Rev. Econ. Stat. 2001, 88, 498-510. [CrossRef]

10. Yin, B. Environmental Regulation and China's Green Total Factor Productivities: Based on the Perspective of Vertical Specialization. China Popul. Resour. Environ. 2012, 22, 60-66.

11. Lv, K.; Chen, Y.; Fan, B. The Relations Study on Environmental Regulation and Green Total Factor Productivity of China's Manufacturing Industry. Ecol. Econ. 2017, 33, 49-52.

12. Cai, N.; Wu, J.; Liu, S. On Environmental Regulation and the Green Industrial Total Factor Productivity-Empirical Analysis Based on the Data of 30 Provinces in China. J. Liaoning Univ. (Philos. Soc. Sci. Ed.) 2014, 42, 65-73.

13. Lei, M.; Yu, X. Local Fiscal Expenditure, Environmental Regulation and the Transition to a Low-Carbon Economy in China. Econ. Sci. 2013, 5, 47-61.

14. Millimet, D.L.; Osang, T. Environmental Regulation and Productivity Growth: An Analysis of U.S. Manufacturing Industries. In Empirical Modeling of the Economy and the Environment; ZEW Economic Studies (Publication Series of the Centre for European Economic Research (ZEW), Mannheim, Germany); Böhringer, C., Löschel, A., Eds.; Physica: Heidelberg, Germany, 2003 ; Volume 20.

15. Granderson, G.; Prior, D. Environmental externalities and regulation constrained cost productivity growth in the US electric utility industry. J. Product. Anal. 2013, 39, 243-257. [CrossRef]

16. Ambec, S.; Barla, P. Can environmental regulations be good for business? An assessment of the porter hypothesis. Energy Stud. Rev. 2006, 14, 42-62. [CrossRef] 
17. Li, C.; Bi, C. Analysis of Industrial Total Factor Productivity Variation in Western Regions Considering Environmental Regulation. J. Xi'an Jiao Tong Univ. (Soc. Sci. Ed.) 2012, 32, 18-22+28.

18. Sun, Y.; Liu, N.; Zhang, Y. Regional Comparison of the Relationship between Environmental Regulation and Total Factor Productivity in China. J. Northeast. Univ. Financ. Econ. 2018, 1, 33-40.

19. Böhringer, C.; Moslener, U.; Oberndorfer, U. Clean and Productive? Empirical Evidence from the German Manufacturing Industry. Res. Policy 2012, 41, 442-451. [CrossRef]

20. Wang, Y.; Shen, N. Environmental regulation and environmental productivity: The case of China. Renew. Sustain. Energy Rev. 2016, 62, 58-766. [CrossRef]

21. Barbera, A.; McConnell, V. The impact of environmental regulations on industry productivity: Direct and indirect effects. J. Environ. Econ. Manag. 1990, 18, 50-65. [CrossRef]

22. Hang, Q.; Hu, J.; Chen, X. Environmental regulation and green total factor productivity: Dilemma or win-win? China Popul. Resour. Environ. 2018, 28, 140-149.

23. Tian, Y.; Lu, S.; Jin, L. Methods, Data and the Difference of TFP Measurement. Quant. Technol. Econ. 2017, 34, $22-40$.

24. Liu, Y.; Li, Z.; Li, J. Comparative Study on DEA Methods of Environmental Efficiency Measurement. J. Math. Pract. Theory 2010, 40, 84-92.

25. Zhao, M.; Liu, F.; Wang, H.; Sun, W. Foreign Direct Investment, Environmental Regulation and Urban Green Total Factor Productivity of the Yellow River Basin. Econ. Geogr. 2020, 40, 38-47.

26. Charnes, A.; Cooper, W.W.; Rhodes, E. Measuring the efficiency of decision-making units. Eur. J. Oper. Res. 1978, 2, 429-444. [CrossRef]

27. Zhou, Y. An Empirical Study of Guangdong Environmental Total Factor Productivity and Its Influencing Factors-Based on Environmental Production Function. Jinan J. (Philos. Soc. Sci.) 2016, 38, 96-112, 132.

28. Tone, K. A slacks-based measure of efficiency in data envelopment analysis. Eur. J. Oper. Res. 2001, 130, 498-509. [CrossRef]

29. Tone, K. A slacks-based measure of super-efficiency in data envelopment analysis. Eur. J. Oper. Res. 2002, 143, 32-41. [CrossRef]

30. Atmospheric Composition Analysis Group. Available online: https:/ / sites.wustl.edu/acag/ (accessed on 31 December 2021).

31. Su, S.; Zhang, F. Modeling the role of environmental regulations in regional green economy efficiency of China: Empirical evidence from super efficiency DEA-Tobit model. J. Environ. Manag. 2020, 261, 110227.

32. Wang, H.; Li, J.; Zhang, X. Evaluation and Influencing Factors of Green Total Factor Productivity of Manufacturing Industry in the Yellow River Basin. Fujian Forum 2021, 10, 127-139.

33. Wu, Y.; Zhang, X. Evaluation of Green Development of Provincial Economy in China-Based on Green Total Factor Productivity. J. Hebei Univ. Econ. Trade 2022, 43, 67-81.

34. Li, D.; Hu, S. How Does Technological Innovation Mediate the Relationship between Environmental Regulation and High-Quality Economic Development? Empirical Evidence from China. Sustainability 2021, 13, 2231. [CrossRef]

35. Yuan, J.; Zhang, D. Research on the Impact of Environmental Regulations on Industrial Green Total Factor Productivity: Perspectives on the Changes in the Allocation Ratio of Factors among Different Industries. Sustainability 2021, 13, 12947. [CrossRef]

36. Yuan, Y.J.; Xie, R.H. FDI, Environmental Regulation and Green Total Factor Productivity Growth of China's Industry: An Empirical Study Based on Luenberger Index. Int. Trade Issues 2015, 8, 84-93.

37. Guo, Y.; Zhang, S.; Zhang, D. The Impacts of Environmental Regulation and Governmental R\&D Funding on Green Technology Innovation: Suppressing or Promoting?-A Literature Review. East China Econ. Manag. 2018, 259, 40-47.

38. Li, B.; Pen, X.; Ou Yang, M. Environmental Regulation, Green Total Factor Productivity and the Transformation of China's Industrial Development Mode-Analysis Based on Data of China's 36 Industries. Chin. Ind. Econ. 2013, 301, 56-68.

39. Li, J.; Wu, M. Dual Environmental Regulation, FDI, and Green Total Factor Productivity: Taking the Three Urban Agglomerations of the Yangtze River Economic Belt as an Example. East China Econ. Manag. 2022, 36, 31-41. 